\title{
Usefulness of Treatment with Topical Antifungals in Burning Mouth Syndrome
}

\author{
Jae Hyung Kim, Hyunjung Kim, Kwang Yoon Jung, and Seung-Kuk Baek \\ Department of Otorhinolaryngology-Head and Neck Surgery, Korea University College of Medicine, Seoul, Korea
}

\section{구강 작열감 증후군에서 국소 항진균제의 치료 효과}

김재형 · 김현정 · 정광윤 · 백승국

고려대학교 의과대학 이비인후-두경부외과학교실

Received August 8, 2019

Revised November 12, 2019

Accepted November 26, 2019

Address for correspondence

Seung-Kuk Baek, MD, PhD

Department of Otorhinolaryngology-

Head and Neck Surgery,

Korea University Anam Hospital,

73 Goryedae-ro, Seongbuk-gu,

Seoul 02841, Korea

Tel $+82-2-920-5486$

Fax $+82-2-920-5233$

E-mail mdskbaek@gmail.com
Background and Objectives Burning mouth syndrome (BMS) is a poorly understood disease that is characterized by burning pain of the tongue without any identifiable organic disease. The pathophysiology of the disease has not been elucidated, and some kind of neuropathies are suspected to be involved. In this study, topical antifungals were prescribed to patients and the authors tried to evaluate its efficacy to BMS.

Subjects and Method 166 patients who had been diagnosed with burning mouth syndrome underwent topical antifungals treatment alone, and then follow-up at 2, 6, and 10 weeks of treatment. Effectiveness of treatment was evaluated by a 0-to- 4 verbal rating scale. All enrolled patients had fungus culture in the oral cavity.

Results A total of 103 patients responded to treatment, accounting for $62 \%$ of the patients. Of those, a total of 63 patients were positive for the fungal culture, which was about $38 \%$ of the patients. There was a statistically significant difference between the initial pain assessment and the pain assessment after 10 weeks in all patients. The rate of response to treatment was not significantly different when classified according to patients' characteristics and comorbidities.

Conclusion The result of the study suggests that topical antifungals are useful for BMS and that it can be used in addition to the systemic medication without the burden of side effects. Additional well-designed studies should be followed to prove the effectiveness of topical antifungals and research on pathophysiology of the disease. Korean J Otorhinolaryngol-Head Neck Surg 2019;62(12):726-30

Key Words Antifungal agents · Burning mouth syndrome · Nystatin.

\section{서 론}

구강 작열감 증후군(burning mouth syndrome)은 구강의 뚜렷한 병변 없이 구강 내의 통증과 불편감을 호소하는 질환 이다.1) 구강 작열감 증후군을 않는 환자들은 다양한 정도의 증상을 호소하며 대개 환자의 전신 상태 혹은 심리적 요인과

This is an Open Access article distributed under the terms of the Creative Commons Attribution Non-Commercial License (https://creativecommons.org/licenses/by-nc/4.0) which permits unrestricted non-commercial use, distribution, and reproduction in any medium, provided the original work is properly cited.
연관이 있는 것으로 알려져 있다..$^{2-4)}$ 구강 작열감 증후군에 는 통일된 기준이 없기 때문에 진단이 어렵고, 연구진에 따 라 서로 다른 역학 조사 결과가 나타나기도 한다. ${ }^{15,6)}$

구강 작열감 증후군에는 다양한 원인 및 악화 요인이 관련 되어 있으며, 전신 인자, ${ }^{78)}$ 국소적 인자, ${ }^{7,-12)}$ 스트레스 및 우 울증과 같은 심리적 요인이 연관되어 있는 것으로 알려져 있 다.,10,11,13-16) 하지만 어떠한 요소가 구강 작열감 증후군의 발 병에 병리학적으로 연관되어 있지는 여전히 명확하지 않다. 따라서 현재 구강 작열감 증후군의 치료는 질환과 관련된 다 
양한 인자를 조절하고 환자가 호소하는 증상을 감소시키는 것을 목적으로 하고 있다.

아직까지 구강 작열감 증후군의 치료에 승인된 약물은 없으 나 trazodone, paroxetine, clonazepam, gabapentin이 50\% 이상의 환자에서 효과가 있는 것으로 여러 연구에서 보고되었 다. ${ }^{17-20)}$ 국소 치료 요법으로는 alpha lipoic acid를 사용하여 약 50 97\%, ${ }^{16,21)}$ steroid gargle을 사용하여 약 50\%, ${ }^{16)}$ benzydamine gargle을 사용하여 $10 \%,{ }^{22)}$ systemic capsaicin을 사 용하여 $76 \%,{ }^{23)}$ topical clonazepam을 사용하여 52 76\%의 효 과를 거두었다고 하는 다수의 연구 결과가 있었다. 23,24$)$

다른 연구들에서는 구강 캔디다증이 설통 및 구강 작열감 이 원인이 될 수 있으며, 구강 작열감 증후군 환자와 대조군 을 비교하였을 때 진균 배양 검사 양성률이 유의미하게 높다 는 연구 결과를 보고하고 있었다. ${ }^{25,26)}$ 하지만 진균 치료의 효 용성에 대해서는 이견이 있었으며 Terai와 Shimahara ${ }^{25)}$ 는 진균 치료 후 증상의 뚜렷한 호전이 있음을 보고하였으나, Park 등' ${ }^{26}$ 은 진균 배양에서 양성인 환자들에게 진균 치료를 시행하였음에도 증상 호전에 유의한 영향은 없었음을 보고 하였다. 따라서 저자들은 구강 내 캔디다와 같은 진균 감염 이 구강 작열감 증후군과 연관이 있다는 것에 주목하여, 구 강 작열감 증후군으로 진단된 환자들에 대한 국소 항진균제 의 효용성을 알아보고자 하였다.

\section{대상 및 방법}

2014 2019년까지 6년간 총 358명의 환자가 구강 내 통증 을 주소로 내원하였다. 이 중에서 구강 작열감 증후군으로 진단된 후 10 주의 외래 추적 관찰 및 국소 항진균제 가글 단 독 치료를 받은 환자를 연구에 포함하였으며, 구강 내 이상 병변이 발견되거나 치료 기간 중 추적 소실된 환자들은 연구 대상에서 제외하였다. 구강 작열감 증후군은 국제두통질환 분류 제3판(International Classification of Headache Disorders-3)의 진단 기준에 따라, 뚜렷한 구강 내 병변 없이, 3 개월 이상의 기간 동안, 하루 2시간 이상 지속되는 구강 내 작열감 또는 불편감을 호소하는 경우로 정의하였다. ${ }^{27}$ 총 166 명의 환자가 연구에 포함되었다. 연구에 포함된 환자에서 혈액 검사는 complete blood count, electrolyte, AST, ALT, $\mathrm{BUN}$, creatinine, $\mathrm{Zn}$ 을 시행하였으며, 구강 내 세균 배양 검 사와 진균 배양 검사를 시행하였다. 또한, 동반 질환, 복용하 는 약물, 흡연력, 정신질환 병력을 조사하였다.

치료는 nystatin(Nystatin Oral Suspension, 10만 iu/mL, Pharmascience Inc., Montreal, Canada) $5 \mathrm{~mL}$ 를 3분간 입 안에 머금고 있다가 뱉는 식으로 1 일 3회 2주간 시행하였으
며, 치료 시작 후 $2,6,10$ 주에 외래 추적 관찰을 하였다. 증상 평가는 0-to-4 verbal rating scale(VRS-4) 통증 척도를 사 용하였으며, 무통증(0점), 경도의 통증(1점), 중등도의 통증 (2점), 심한 통증(3점), 참을 수 없는 통증(4점)으로 분류하였 다. 치료의 성공은 첫 내원 후 10 주 뒤 시행한 통증 척도 검 사에서 1점 이하의 통증을 호소한 경우로 정하였다.

SPSS 22.0(IBM Corp., Armonk, NY, USA)을 이용하여 평균 분석을 통하여 국소 항진균제 가글 치료의 효과를 분석 하였으며, 이변량 로지스틱 회귀 분석을 통하여 성별, 음주, 흡연 여부 및 동반된 질환과 국소 항진균제 가글 치료 효과 에 대한 반응의 연관성을 분석하였다.

본 연구는 고려대학교 안암병원 생명윤리심의위원회의 검 토와 승인을 받았다(승인번호: 2019AN0342).

\section{결 과}

연구에 포함된 환자 중 119명(71.69\%)이 여성, 47명이 남성 이었으며, 평균 연령은 64.1세였다. 음주를 하지 않거나, 거의 하지 않는 환자는 142 명이었으며, 담배를 피우지 않는 환자 는 143 명이었다. 동반된 질환은 고혈압이 70 명에서 동반되어 가장 흔하게 동반된 질환으로 확인되었으며, 당뇨는 23명에 서 동반되었으며, 우울증 및 불면증 등의 정신질환은 22 명에 서 동반되었다. 아무런 질환도 동반되지 않은 환자는 64 명이 었다(Table 1).

166 명의 환자 중에서 총 103 명(62\%)의 환자가 치료에 반응 이 있는 것으로 확인되었다. 또한 63 명의 환자가 진균 배양 검사에서 진균 감염이 확인되었으며, 이는 전체 환자의 $38 \%$

Table 1. Patients' demographics

\begin{tabular}{lc}
\hline \multicolumn{1}{c}{ Attribute } & $\mathrm{n}(\%)$ \\
\hline Sex & $47 / 119(28.3 / 71.7)$ \\
Male/female & $64.10 \pm 12.80$ \\
Age, mean \pm SD & \\
Alcohol & $110 / 32(66.3 / 19.3)$ \\
Abstainer/rarely & $17 / 7(10.2 / 4.2)$ \\
Weekly/daily & \\
Smoking & $128 / 15(77.1 / 9.0)$ \\
Never smoked/quit smoking & $23(13.9)$ \\
Current smoker & \\
Comorbidity & $23(13.9)$ \\
Diabetes mellitus & $70(42.2)$ \\
Hypertension & $7(4.2)$ \\
Hepatic disease & $22(13.3)$ \\
Psychiatric-neurologic & $23(13.9)$ \\
Others & $75.29 \pm 13.02$ \\
Serum zinc level, mean \pm SD & \\
\hline
\end{tabular}


에 해당하였다. 치료 기간 동안 미각 변화 또는 텁텁함 등 가 글 치료로 인해 가능한 불편감이 나타난 사례는 없었다. 통 증의 감소는 진균 배양 검사에서 진균이 확인된 환자 중 $65 \%$ 에서, 진균이 확인되지 않은 환자 중 $61 \%$ 에서 확인되었 으며, 치료 전과 치료 후 통증 점수는 통계적 유의한 차이가 확인되었다 $(p<0.0001)$ (Fig. 1). 치료 효과를 나타낸 환자군 과 치료 효과가 나타나지 않았을 경우를 비교하였을 때, 치 료 효과가 나타나지 않은 환자군에서는 초기 내원할 당시와 비교하여 통증 정도에 거의 변화가 없었으나, 치료 효과가 나 타난 환자군에서는 통증 점수가 치료 기간이 길어짐에 따라 점진적으로 감소하는 것이 확인되었다(Fig. 2).

환자의 통증 평가 점수(VRS-4)에 기초하여 항진균제의 치료 성공을 예측하기 위한 cut-off point값을 결정하기 위 해 receiver operating characteristic(ROC) 곡선을 구현하였 다. 치료 시작 후 2 주가 된 환자의 통증 평가 점수에 대한 ROC 곡선의 곡선 밑 면적 area under the curve는 0.873 이 었다. 치료 시작 후 2 주 뒤 치료 성공을 예측하기위한 통증 평가 점수의 cut-off point값은 2점이었으며 88.5\%의 민감도 와 $83.9 \%$ 의 특이도를 나타내었다(Fig. 3).

치료 전에 치료 효과를 예측할 수 있는 요인을 알아보고자 성별, 음주, 흡연, 동반된 질환에 따라 환자군을 분류하여 치 료에 반응을 보인 환자의 비율을 비교하였을 때, 어떠한 요인 도 항진균제에 대한 반응을 예측하는 데 도움을 주지 않는 것으로 확인되었다(Table 2).

\section{고 찰}

기존 연구들을 통하여 paroxetine, clonazepam, gabapentin과 같은 신경안정제 혹은 항우울제 복용이 구강 작열 감 증후군의 증상을 조절하는 데 도움이 되는 것으로 알려 져 있다. 이러한 약물들을 사용하여 구강 작열감 증후군을 치료한 다른 연구들의 결과를 보면 paroxetine은 $66.7 \%$ 의 환자에서, clonazepam은 $57.1 \%$ 의 환자에서, gabapentin을 $85.7 \%$ 의 환자에서 성공적인 치료 결과를 확인할 수 있었다 고 한다. ${ }^{17-20)}$ 하지만 신경안정제나 항우울제 복용은 동반된 정신질환으로 이미 해당 약제를 복용하는 환자들에서 사용 하기가 어려움이 있으며, 진정, 두드러기, 어지럼 등 더 이상 치료를 유지하기 힘들 정도의 부작용을 호소하는 환자들이 있는 것으로 보고되고 있다. ${ }^{28)}$ 본 연구에서 사용한 국소 항 진균제 가글은 약 $62 \%$ 의 환자에서 치료에 반응을 보였으며, 진균 배양 검사에서 음성으로 확인된 환자들에서도 약 $61 \%$ 환자에서 치료에 반응을 보이는 것으로 확인되었다. 진균 검 사에서 음성이 확인된 환자들에서 치료에 반응을 보인 것은

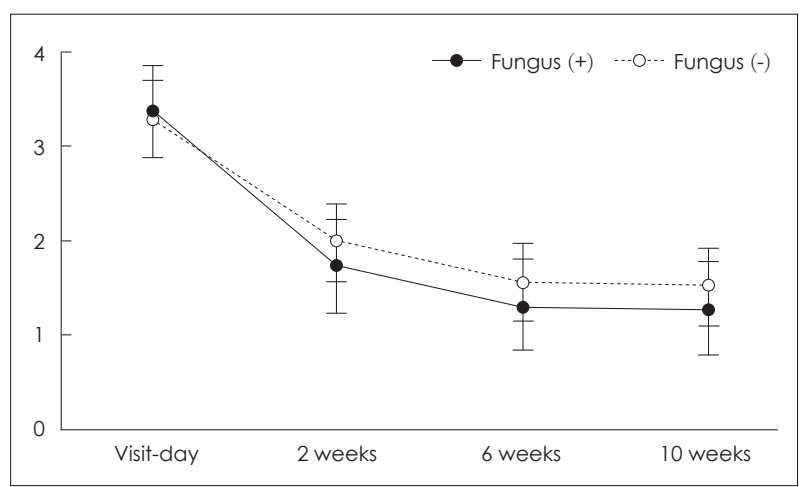

Fig. 1. Changes in pain scores after topical antifungal therapy in patients with positive fungal culture (solid line) and patients with negative fungal culture (dotted line).

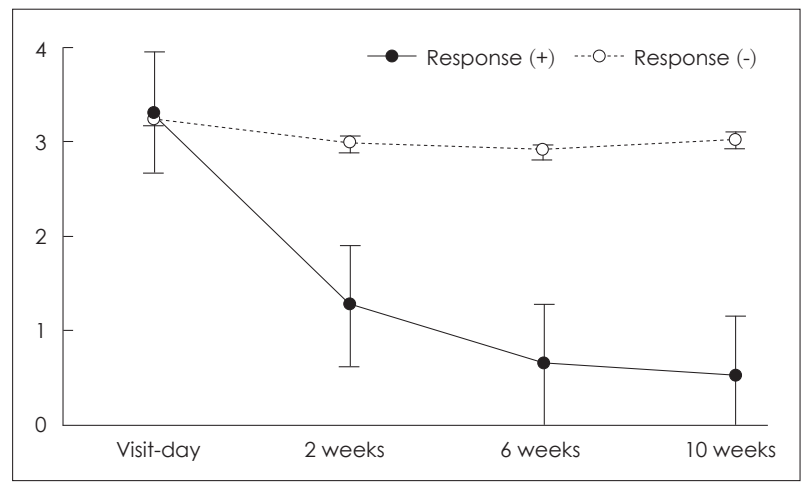

Fig. 2. Changes in pain scores after topical antifungal therapy based on drug response. The patients in whom pain scores were alleviated after topical antifungal treatment (solid line). The patients without improvement (dotted line).

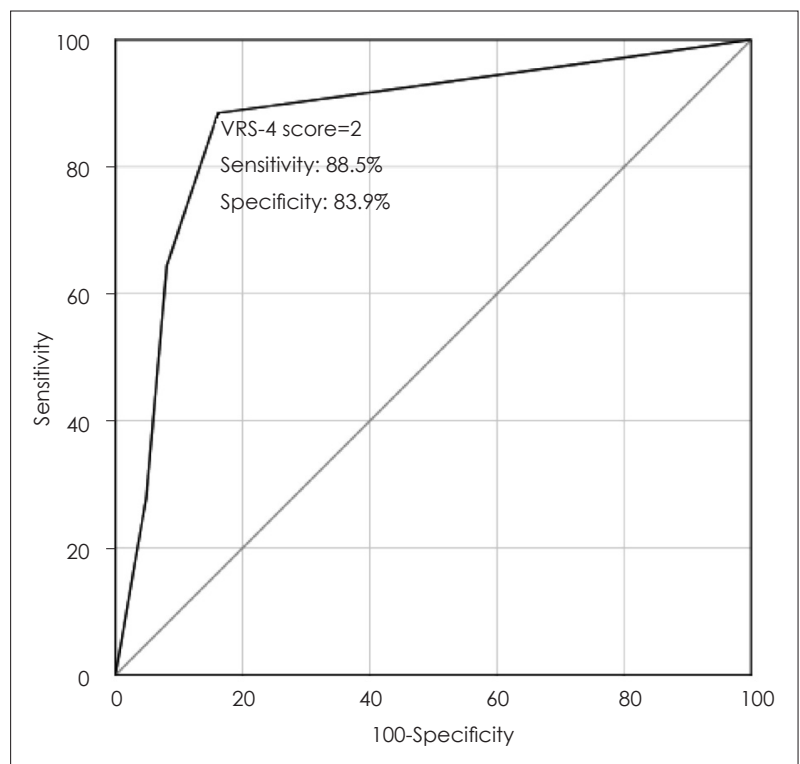

Fig. 3. receiver operating characteristic curve for predicting treatment success with topical antifungal agent based on VRS-4 score at 2 weeks after treatment. VRS: verbal rating scale. 
Table 2. Summary of multiple binary logistic regression analysis

\begin{tabular}{lccccc}
\hline \multicolumn{1}{c}{ Variable } & $\beta$ & SE & p-value & OR & $95 \% \mathrm{Cl}$ \\
\hline Sex (female) & -0.40 & 0.42 & 0.34 & 0.67 & $0.29-1.53$ \\
Alcohol & -0.78 & 0.62 & 0.20 & 0.46 & $0.14-1.53$ \\
Smoking & 0.60 & 0.59 & 0.31 & 1.82 & $0.57-5.81$ \\
Diabetes mellitus & -0.21 & 0.53 & 0.69 & 0.81 & $0.29-2.28$ \\
Hypertension & -0.46 & 0.55 & 0.39 & 0.63 & $0.22-1.83$ \\
Hepatic disease & -0.25 & 0.97 & 0.79 & 0.78 & $0.12-5.20$ \\
Psycho-neurologic disease & 0.43 & 0.53 & 0.42 & 1.53 & $0.55-4.29$ \\
Others & -0.47 & 0.62 & 0.45 & 0.63 & $0.19-2.10$ \\
\hline
\end{tabular}

SE: standard error, OR: odds ratio, Cl: confidence interval

진균 검사의 위음성에 의한 것으로 생각된다. 이번 연구에 사용된 진균 염색 및 진균 배양 검사의 위음성률은 약 20 40\%인 것으로 보고되고 있다. ${ }^{29)}$ 따라서 저자들은 진균 검사 결과와 상관없이 국소 항진균제를 사용해보는 것이 구 강 작열감 증후군 환자의 증상을 경감시키는 데 효과가 있는 것으로 생각되었다. 기존에 일반적으로 사용되는 신경안정제 및 항우울제를 사용한 경우와 비슷한 정도의 치료 효과를 보이고 있으며, 약물 복용으로 인한 진정, 두드러기, 어지럼 등의 부작용이 거의 발생하지 않는다는 점에서 구강 작열감 증후군 치료에 유용성이 있을 것으로 생각된다.

다만 국소 항진균제에 반응을 보이지 않는 환자들의 10 주 간의 관찰에 따른 통증 점수의 변화를 보았을 때, 국소 항진 균제 가글 치료에 반응을 보이지 않는 환자들은 치료 기간이 길어진다 하더라도 치료에 거의 반응을 보이지 않는다는 것 을 알 수 있었고, 이러한 환자들에 대해서는 기존에 사용하 는 진통제 및 신경안정제 투여가 필요할 것으로 생각된다. 본 연구의 한계점은 치료 효과 판정에 사용된 VRS-4 통증 척 도가 직관적이고 이해하기 쉬우며, 환자의 표현에 근거하기 때문에 사용하기 쉽다는 장점이 있지만, 환자의 표현에 따라 서 통증 점수 평가가 다소 모호할 수 있다는 단점이 있으며, 국소 항진균제를 사용한 환자군에 비교할 대조군이 존재하 지 않는다는 단점이 있다. 따라서 향후 국소 항진균제가 구강 작열감 증후군의 치료에 어느 정도의 효과를 갖는지를 비교 하기 위한 전향적인 연구가 필요할 것으로 생각된다.

\section{Acknowledgments}

None.

\section{ORCID}

Seung-Kuk Baek https://orcid.org/0000-0002-4751-0337

\section{REFERENCES}

1) Zakrzewska JM, Forssell H, Glenny AM. Interventions for the treatment of burning mouth syndrome: A systematic review. J
Orofac Pain 2003;17(4):293-300.

2) Forssell H, Teerijoki-Oksa T, Kotiranta U, Kantola R, Bäck M, Vuorjoki-Ranta TR, et al. Pain and pain behavior in burning mouth syndrome: A pain diary study. J Orofac Pain 2012;26(2):117-25.

3) Abetz LM, Savage NW. Burning mouth syndrome and psychological disorders. Aust Dent J 2009;54(2):84-93.

4) Ritchie A, Kramer JM. Recent advances in the etiology and treatment of burning mouth syndrome. J Dent Res 2018;97(11): 1193-9.

5) Evans RW, Drage LA. Burning mouth syndrome. Headache 2005;45(8):1079-81.

6) Danhauer SC, Miller CS, Rhodus NL, Carlson CR. Impact of criteria-based diagnosis of burning mouth syndrome on treatment outcome. J Orofac Pain 2002;16(4):305-11.

7) Rodríguez-de Rivera-Campillo E, López-López J. Evaluation of the response to treatment and clinical evolution in patients with burning mouth syndrome. Med Oral Patol Oral Cir Bucal 2013; 18(3):e403-10.

8) Koszewicz M, Mendak M, Konopka T, Koziorowska-Gawron E, Budrewicz S. The characteristics of autonomic nervous system disorders in burning mouth syndrome and Parkinson disease. J Orofac Pain 2012;26(4):315-20.

9) López-Jornet P, Camacho-Alonso F, Andujar-Mateos P, SánchezSiles M, Gómez-Garcia F. Burning mouth syndrome: An update. Med Oral Patol Oral Cir Bucal 2010;15(4):e562-8.

10) Lamey PJ, Lewis MA. Oral medicine in practice: Burning mouth syndrome. Br Dent J 1989;167(6):197-200.

11) Lamey PJ. Burning mouth syndrome. Dermatol Clin 1996;14(2): $339-54$.

12) Klasser GD, Fischer DJ, Epstein JB. Burning mouth syndrome: Recognition, understanding, and management. Oral Maxillofac Surg Clin North Am 2008;20(2):255-71,vii.

13) Adamo D, Schiavone V, Aria M, Leuci S, Ruoppo E, Dell'Aversana $\mathrm{G}$, et al. Sleep disturbance in patients with burning mouth syndrome: A case-control study. J Orofac Pain 2013;27(4):304-13.

14) Lauria G, Majorana A, Borgna M, Lombardi R, Penza P, Padovani A, et al. Trigeminal small-fiber sensory neuropathy causes burning mouth syndrome. Pain 2005;115(3):332-7.

15) Mock D, Chugh D. Burning mouth syndrome. Int J Oral Sci 2010;2(1):1-4.

16) Femiano F, Gombos F, Scully C. Burning mouth syndrome: Open trial of psychotherapy alone, medication with alpha-lipoic acid (thioctic acid), and combination therapy. Med Oral 2004;9(1):8-13.

17) Tammiala-Salonen T, Forssell H. Trazodone in burning mouth pain: A placebo-controlled, double-blind study. J Orofac Pain 1999;13(2):83-8.

18) Maina G, Vitalucci A, Gandolfo S, Bogetto F. Comparative efficacy of SSRIs and amisulpride in burning mouth syndrome: A 
single-blind study. J Clin Psychiatry 2002;63(1):38-43.

19) Grushka M, Epstein J, Mott A. An open-label, dose escalation pilot study of the effect of clonazepam in burning mouth syndrome. Oral Surg Oral Med Oral Pathol Oral Radiol Endod 1998;86(5): 557-61.

20) Ben-David B, Friedman M. Gabapentin therapy for vulvodynia. Anesth Analg 1999;89(6):1459-60.

21) Femiano F. Burning mouth syndrome (BMS): An open trial of comparative efficacy of alpha-lipoic acid (thioctic acid) with other therapies. Minerva Stomatol 2002;51(9):405-9.

22) Woda A, Navez ML, Picard P, Gremeau C, Pichard-Leandri E. A possible therapeutic solution for stomatodynia (burning mouth syndrome). J Orofac Pain 1998;12(4):272-8.

23) Petruzzi M, Lauritano D, De Benedittis M, Baldoni M, Serpico R. Systemic capsaicin for burning mouth syndrome: Short-term results of a pilot study. J Oral Pathol Med 2004;33(2):111-4.

24) Gremeau-Richard C, Woda A, Navez ML, Attal N, Bouhassira D,
Gagnieu MC, et al. Topical clonazepam in stomatodynia: A randomised placebo-controlled study. Pain 2004;108(1-2):51-7.

25) Terai $\mathrm{H}$, Shimahara M. Atrophic tongue associated with Candida. J Oral Pathol Med 2005;34(7):397-400.

26) Park H, Kim Y, Jeong WJ, Ahn SH. Analysis of relationship between burning mouth syndrome and abnormality of serum examination. Korean J Otorhinolaryngol-Head Neck Surg 2013; 56(1):23-7.

27) Olesen J. International classification of headache disorders. Lancet Neurol 2018;17(5):396-7.

28) Choi HG, Jung EJ, Lee WY, Kim H, Cha W, Hah JH. Comparison of pharmacological treatments for burning mouth syndrome. Korean J Otorhinolaryngol-Head Neck Surg 2012;55(11):707-11.

29) Terai H, Shimahara M. Usefulness of culture test and direct examination for the diagnosis of oral atrophic candidiasis. Int $\mathrm{J}$ Dermatol 2009;48(4):371-3. 